CLINICAL STUDY

\title{
Fiber intake predicts ghrelin levels in overweight and obese postmenopausal women
}

\author{
David H St-Pierre ${ }^{1, \dagger}$, Rémi Rabasa-Lhoret ${ }^{1,3,4}$, Marie-Ève Lavoie ${ }^{1}$, Antony D Karelis ${ }^{5}$, Irene Strychar ${ }^{1}$, Eric Doucet $^{6}$ \\ and Lise Coderre ${ }^{2}$ \\ Département de ${ }^{1}$ Nutrition et de ${ }^{2}$ Médecine, Université de Montréal, Montréal, Québec, Canada, ${ }^{3}$ Montreal Diabetes Research Centre, Centre Hospitalier de \\ l'Université de Montréal, Montréal, Québec, Canada, ${ }^{4}$ Institut de Recherches Cliniques de Montréal, 110 Ave Des Pins Ouest, Montréal, Québec, Canada \\ H2W 1R7, ${ }^{5}$ Département de Kinanthropologie, Université du Québec à Montréal, Montréal, Québec, Canada and ${ }^{6}$ Faculty of Health Sciences, School of \\ Human Kinetics, University of Ottawa, Ottawa, Ontario, Canada
}

(Correspondence should be addressed to R Rabasa-Lhoret at Institut de Recherches Cliniques de Montréal; Email: remi.rabasa-Ihoret@umontreal.ca)

${ }^{\dagger}$ (D H St-Pierre is now at Division of Endocrinology, Department of Internal Medicine, Molinette Hospital, University of Turin, Turin, Italy)

\begin{abstract}
Background: Ghrelin levels are decreased upon food intake, but the impact of specific diet-derived macronutrients on its regulation remains unclear. In addition, because of ghrelin's association with body weight regulation, it is important to understand the mechanisms regulating its levels in obese individuals.

Objective: To examine the effect of specific macronutrients on ghrelin levels in overweight and obese postmenopausal women.

Methods: Thirty-five subjects underwent a euglycemic/hyperinsulinemic clamp (EHC) to examine glucose disposal and total ghrelin (TotG) and acylated ghrelin (AG) levels. Macronutrient intake was evaluated with a 3-day food questionnaire.

Results: Under fasting conditions, positive associations were observed between fiber intake and TotG and AG levels. Fasting AG also correlated positively with the intake of total energy, as well as monounsaturated and polyunsaturated lipids. Importantly, fiber consumption explained up to 26 and $23 \%$ of the variation in TotG and AG respectively. During the EHC, TotG levels were significantly reduced at all times, while AG was decreased at 60 min only. TotG area under the curve (AUC) values were positively associated with fiber and polyunsaturated lipid intake, while AG AUC values correlated positively with fiber, total energy, carbohydrate, and lipid intake. Interestingly, fiber intake explained up to $21 \%$ of the variation in TotG AUC, while total energy intake predicted up to $21 \%$ of the variation in the AG AUC.

Conclusion: The present study suggests that fiber intake is an important regulator of ghrelin levels both in fasting and in hyperinsulinemic conditions. Overall, these results reinforce the importance of the intimate association between eating habits and gastrointestinal hormonal regulation.
\end{abstract}

European Journal of Endocrinology $16165-72$

\section{Introduction}

Ghrelin is a 28 amino acid hormone mainly derived from the fundus of the stomach (1). Although it was first recognized for its stimulatory effect on somatotrope cells of the anterior pituitary gland, ghrelin also plays a physiological role in the regulation of food intake and metabolic functions (2-4). In lean healthy subjects, ghrelin levels increase before meals, whereas they are significantly lower under postprandial conditions $(5,6)$. By contrast, in individuals with obesity, insulin resistance (IR), or type 2 diabetes, fasting ghrelin levels are lower and the postprandial inhibition is either of lesser amplitude or undetectable compared with lean individuals $(7,8)$. Thus, metabolic alterations are associated with important changes in circulating ghrelin levels.

In the circulation, total ghrelin (TotG) is present as acylated ghrelin (AG) and unacylated ghrelin (UAG) forms. Adding to the complexity, these two distinct forms share some common functions, but also display opposite biological activities. For instance, orexigenic and diabetogenic effects are associated with AG $(3,4)$, whereas evidence suggests that UAG could have antidiabetogenic functions (9-13). Although there is a characteristic decrease in ghrelin levels following food intake, the molecular mechanisms underlying this physiological response are still unclear. Importantly, 
there is limited information regarding the impact of specific dietary macronutrients on both fasting and postprandial ghrelin fluctuations $(14,15)$, and no consensus has emerged regarding the acute effects of high-carbohydrate, high-lipid, or high-protein intake on ghrelin levels (16-19).

Fiber-rich diets have a beneficial effect on insulin sensitivity and plasma lipid profiles (20). In addition, epidemiological studies demonstrated that high fiber uptake has a beneficial effect on body weight (21), and could help lower the risks of both diabetes (22) and cardiovascular diseases $(23,24)$. Furthermore, fiber consumption has been shown to promote satiety through modulation of the perception of satiety (21). These effects have been attributed, in part, to the slower gastric emptying and macronutrient absorption from the gut after fiber consumption (20).

Due to ghrelin's gastrointestinal nature and its dual acute and chronic impact on the regulation of energy balance $(25,26)$, we hypothesized that ghrelin levels may be influenced by the consumption of specific dietary macronutrients. Since the mechanisms underlying AG and UAG regulation may differ $(7,27)$, the present study evaluates the impact of food intake, as measured by a 3-day food questionnaire, on ghrelin profiles (determined by TotG and AG values) in both fasting conditions and during a hyperinsulinemic state induced by the euglycemic/hyperinsulinemic clamp (EHC) technique.

\section{Materials and methods}

\section{Subjects}

The study population consisted of 35 non-diabetic overweight or obese postmenopausal women aged between 46 and 68 years old. These women were recruited as part of the larger Montreal Ottawa New Emerging Team study. Women were included in the study if they met the following criteria: i) body mass index $(\mathrm{BMI}) \geq 27 \mathrm{~kg} / \mathrm{m}^{2}$; ii) $\mathrm{FSH}$ levels $\geq 30 \mathrm{U} / \mathrm{l}$; iii) sedentary $(<2 \mathrm{~h} /$ week of structured exercise); iv) non-smokers; v) low to moderate alcohol consumption ( $<2$ drinks/day); vi) absence of any known inflammatory disease; and vii) no use of hormone replacement therapy within the last 3 months. On physical examination or biological testing, all participants had no history or evidence of: i) cardiovascular diseases, peripheral vascular diseases, or stroke; ii) diabetes as evaluated by a $2-\mathrm{h} 75 \mathrm{~g}$ oral glucose tolerance test; iii) orthopedic limitations; iv) uncontrolled thyroid or pituitary diseases; v) infection (medical questionnaire examination and complete blood count); and vi) medication that could affect cardiovascular function and/or metabolism. The study was approved by the University of Montreal Ethics Committee.

\section{Sequence of tests}

After reading and signing the consent form, each participant was invited to the metabolic unit for a series of tests. At inclusion, all subjects had a BMI $\geq 27 \mathrm{~kg} / \mathrm{m}^{2}$. On testing day, one subject displayed a BMI slightly below $27 \mathrm{~kg} / \mathrm{m}^{2}$, due to a slight weight loss during the stabilization period. This subject was included in the analysis based on the observed BMI at inclusion. After a 4-week weight stabilization period, patients underwent a 3-h EHC. Body composition was determined by dual energy X-ray absorptiometry (DXA).

\section{Euglycemic/hyperinsulinemic clamp}

The test began at 0730 after a 12-h overnight fast following the procedure described by DeFronzo et al. (28). A catheter was introduced in the antecubital vein for the infusion of $20 \%$ dextrose and insulin (Actrapid, Novo-Nordisk, Toronto, Ontario, Canada). Another catheter was inserted into the other arm for blood sampling. Three fasting samples of plasma glucose and insulin were collected over $40 \mathrm{~min}$. Then, insulin was infused at the rate of $75 \mu \mathrm{U} / \mathrm{m}^{2}$ per min for $180 \mathrm{~min}$. Plasma glucose was measured every $10 \mathrm{~min}$ with a glucose analyzer (Beckman Instruments, Fullerton, CA, USA) and maintained at fasting level with a variable infusion rate of $20 \%$ dextrose. Glucose disposal (insulin sensitivity) was calculated as the mean rate of glucose infusion measured during the last $30 \mathrm{~min}$ of the clamp steady state and was expressed as $\mathrm{mg} / \mathrm{min}$ per $\mathrm{kg}$ of fat-free mass.

\section{Blood samples}

After a 12-h overnight fast, blood samples were collected at times $0,60,160,170$, and 180 min during the EHC for TotG and AG measurements. Fasting serum samples of triglyceride, high-density lipoproteins (HDL)cholesterol, low-density lipoproteins (LDL)-cholesterol, insulin, and glucose concentrations were analyzed at $0 \mathrm{~min}$. Blood samples were centrifuged at $3900 \boldsymbol{g}$ for $10 \mathrm{~min}$ at $4{ }^{\circ} \mathrm{C}$ and kept at $-80^{\circ} \mathrm{C}$ until further analyses. For AG samples, $1 \mathrm{ml}$ of plasma was treated with $50 \mu \mathrm{l} / \mathrm{ml} \mathrm{HCl}(1 \mathrm{M})$ and $10 \mu \mathrm{l} / \mathrm{ml}$ phenylmethylsulfonyl fluoride (57.4 mM; Sigma-Aldrich, St Louis, MO, USA) to prevent peptidic degradation and/or loss of the acyl group on $\mathrm{Ser}^{3}$. Plasma immunoreactive TotG and AG levels were measured in duplicate with a commercial RIA procedure using ${ }^{125}$ I-labeled bioactive human TotG and AG as tracers and a rabbit polyclonal antibody raised against full-length peptides (Linco Research, St-Charles, MO, USA). As indicated by the manufacturer, inter- and intra-assay percent coefficients of variation $(\mathrm{CV})$ were respectively under 18 and $10 \%$. Blood glucose and the lipid profile were analyzed on the day of collection, while insulin samples were kept at $-80^{\circ} \mathrm{C}$ until analysis. Analyses for total cholesterol, 
HDL-cholesterol, and triglycerides were done on the COBAS INTEGRA 400 analyzer (Roche Diagnostic). Total cholesterol, HDL-cholesterol, and triglycerides were used in the Friedewald formula (29) to calculate LDL-cholesterol concentration. Insulin levels were determined by RIA (Linco Research). Homeostasis model assessment for IR was calculated according to the formula of Matthews et al. (30).

\section{Body composition}

Body weight was measured using an electronic scale (Balances Industrielles, Montreal, Quebec, Canada), and standing height was measured using a wall stadiometer (Perspective Enterprises, Portage, MI, USA). Lean body mass and total adiposity were measured by DXA (General Electric Lunar Corporation version 6.10.019, Madison, WI, USA). Percentage CV was $0.8 \%$ for lean body mass and $1.1 \%$ for total adiposity.

\section{Computed topography}

We evaluate visceral and subcutaneous fat areas at the L4-L5 level using a scout image of the body with a GE High-Speed Advantage computed topography (CT) scanner (General Electric Medical Systems, Milwaukee, WI, USA). Subjects were examined in the supine position with both arms stretched above their head. Visceral adipose tissue (VAT) area was quantified by delineating the intra-abdominal cavity at the most internal aspect of the abdominal and oblique muscle walls surrounding the cavity and the posterior aspect of the vertebral body. Test-retest measures of the different body fat distribution compartments on ten CT scans yielded a mean absolute difference of $1 \%$ in obese postmenopausal women (31).

\section{Nutrient intakes}

Food intake was assessed using a 3-day food record (1) at baseline, during the weight stabilization period. Subjects were instructed by a registered dietitian to keep a record of food intake, including condiments and beverages, over 2 weekdays and 1 weekend day while maintaining their usual habits. Each food record was reviewed by a registered dietitian with the subject to complete missing information. Analyses were conducted with the Food Processor SQL program (Food Processor SQL Edition, version 9.6.2, 2004, ESHA Research, Salem, OR, USA) using the 2001 Canadian nutrient data file and the USDA database. The total energy intake was calculated by the Food Processor program and represents gross energy intake.

The data entry of the food records was done by a registered dietitian and independently verified by a second one. Discrepancies between the two registered dietitians were discussed and modifications were made according to their mutual decision. Mean intake of 3 days for total energy, carbohydrates, protein, and fat was calculated for each subject (32).

\section{Statistical analysis}

The data are expressed as the mean \pm s.D. A repeated measures ANOVA was used to detect a significant effect of time within the $\mathrm{EHC}(0$ vs $60,160,170$, and $180 \mathrm{~min}$ ). If a significant time interaction was observed, a Bonferroni test was used to identify the differences between fasting and other values throughout the clamp. The area under the curve (AUC) was assessed to provide an overall index of ghrelin suppression throughout the EHC and was calculated by the trapezoidal method. The relationships of TotG and AG with macronutrient intakes were evaluated by Pearson's correlation. Partial correlations were used to control for specific variables. A stepwise multi-linear regression model determined which variables (fiber, carbohydrate, total lipid, polyunsaturated and monounsaturated lipids, omega-3 fatty acids, and total energy intake) explained the unique variance in TotG and AG profiles. Statistical analyses were performed with SPSS for Windows version 11.5. Significance was accepted at $P<0.05$.

\section{Results}

Thirty-five overweight and obese postmenopausal women were included in the present study with an average age of $57.6 \pm 5.0$ years. As presented in Tables 1 and 2, these subjects displayed important variations in body composition, lipid profile, glucose disposal, and nutrient intake.

As described in Table 3, fasting TotG was positively associated with fiber intake $(r=0.51 ; P<0.005)$. Similarly, and as shown in Table 4, fasting AG levels also correlated positively with fiber intake $(r=0.47$; $P<0.01)$. In addition, fasting AG correlated with total energy intake $(r=0.37 ; P<0.05)$ as well as monounsaturated $(r=0.40 ; P<0.05)$, polyunsaturated

Table 1 Subject metabolic characteristics.

\begin{tabular}{lcc}
\hline Characteristics & Mean \pm s.D. & Range \\
\hline BMI $\left(\mathrm{kg} / \mathrm{m}^{2}\right)$ & $33.9 \pm 5.4$ & $26.9-45.0$ \\
Visceral adiposity $\left(\mathrm{cm}^{2}\right)$ & $187 \pm 54$ & $96-346$ \\
Total cholesterol $(\mathrm{mmol} / \mathrm{l})$ & $5.51 \pm 0.66$ & $4.01-6.94$ \\
$\mathrm{HDL}(\mathrm{mmol} / \mathrm{l})$ & $1.42 \pm 0.27$ & $0.99-2.17$ \\
$\mathrm{LDL}(\mathrm{mmol} / \mathrm{l})$ & $3.23 \pm 0.68$ & $1.43-5.09$ \\
Triglycerides $(\mathrm{mmol} / \mathrm{l})$ & $1.87 \pm 0.66$ & $0.94-3.82$ \\
Fasting glycemia $(\mathrm{mmol} / \mathrm{l})$ & $5.0 \pm 0.4$ & $4.3-5.8$ \\
Fasting insulin $\mu \mathrm{U} / \mathrm{ml}(n=34)$ & $15.8 \pm 7.4$ & $7.3-44.5$ \\
HOMA $(n=34)$ & $3.50 \pm 1.69$ & $1.45-9.50$ \\
Glucose disposal rate $(\mathrm{mg} / \mathrm{min}$ & $10.9 \pm 3.6$ & $4.7-19.0$ \\
$\quad$ per kg FFM) & &
\end{tabular}

BMI, body mass index; HDL, high-density lipoproteins; LDL, low-density lipoproteins; HOMA, homeostasis model assessment; FFM, fat-free mass. 
Table 2 Energy and nutrient intakes.

\begin{tabular}{llc}
\hline Nutrients & Mean \pm s.D. & Range \\
\hline Total energy intake (kcal/day) & $1999 \pm 524$ & $1118-3552$ \\
Total protein intake (g/day) & $82.8 \pm 20.6$ & $38.3-132.1$ \\
Total carbohydrate intake & $244 \pm 66$ & $160-433$ \\
$\quad$ (g/day) & & \\
$\quad \begin{array}{l}\text { Total lipid intake (g/day) } \\
\text { Monounsaturated lipid intake }\end{array}$ & $74.5 \pm 27.8$ & $32.3-148.9$ \\
$\quad$ (g/day) & $25.4 \pm 11.1$ & $10.6-56.6$ \\
$\begin{array}{l}\text { Polyunsaturated lipid intake } \\
\quad \text { g/day) }\end{array}$ & $11.9 \pm 6.3$ & $4.1-30.1$ \\
Omega-3 intake (g/day) & $0.42 \pm 0.63$ & $0.00-2.71$ \\
Fiber intake (g/day) & $19.6 \pm 7.6$ & $9.7-40.7$ \\
\hline
\end{tabular}

$(r=0.41 ; P<0.05)$, and omega-3 $(r=0.35 ; P<0.05)$ lipid intakes. Importantly, the correlation between fiber intake and fasting $\mathrm{AG}$ and TotG levels remained statistically significant after correcting for fasting glycemia, glucose infusion rate during the $\mathrm{EHC}$ and total energy intake (data not shown). Furthermore, fiber consumption explained up to 26 and $23 \%$ of the variation in TotG and AG respectively (Table 5).

During the EHC baseline values were significantly reduced at all times for TotG and only at time $60 \mathrm{~min}$ for AG (Figure 1). TotG AUC values were positively associated with fiber $(r=0.46 ; P<0.01)$ and polyunsaturated lipid intake $(r=0.34 ; P<0.05)$. Similarly, AG AUC values were also positively correlated with fiber $(r=0.45 ; P<0.01)$ as well as total energy $(r=0.46$; $P<0.01)$ and carbohydrate $(r=0.41 ; P<0.05)$ intake. In addition, total $(r=0.37 ; P<0.05)$, monounsaturated $(r=0.41 ; \quad P<0.05), \quad$ polyunsaturated $\quad(r=0.46$; $P<0.01)$, and omega-3 $(r=0.41 ; P<0.05)$ lipid intake values were significantly associated with those of $A G$ AUC. Association between fiber intake and ghrelin TotG AUC remained significant after correction for fasting glycemia, glucose infusion rate during the $\mathrm{EHC}$, and total energy intake. However, the association between AG AUC and fiber intake did not remain significant after correction for total energy intake. Fiber intake explained up to $21 \%$ of the variation in TotG AUC, while total energy and omega-3 intake explained $33 \%$ of the variation in AG AUC.

Table 3 Association between total ghrelin profile and nutrient intake.

\begin{tabular}{lcc}
\hline Variables & $\begin{array}{c}\text { TotG } \\
\text { (fasting) }\end{array}$ & $\begin{array}{c}\text { TotG AUC } \\
\text { (EHC) }\end{array}$ \\
\hline Total energy intake & $\mathrm{NS}$ & $\mathrm{NS}$ \\
Total carbohydrate intake & $\mathrm{NS}$ & $\mathrm{NS}$ \\
Total lipid intake & $\mathrm{NS}$ & $\mathrm{NS}$ \\
Monounsaturated lipid intake & $\mathrm{NS}$ & $\mathrm{NS}$ \\
Polyunsaturated lipid intake & $\mathrm{NS}$ & $r=0.34^{*}$ \\
Omega-3 intake & $\mathrm{NS}$ & $\mathrm{NS}$ \\
Fiber intake & $r=0.51^{\ddagger}$ & $r=0.46^{\dagger}$ \\
\hline
\end{tabular}

TotG, total ghrelin; AUC, area under the curve; EHC, euglycemic/ hyperinsulinemic clamp. ${ }^{\star} P<0.05 ;{ }^{\dagger} P<0.01 ;{ }^{\ddagger} P<0.005$.
Table 4 Association between acylated ghrelin (AG) profile and nutrient intake.

\begin{tabular}{lll}
\hline Variables & $\begin{array}{l}\text { AG } \\
\text { (fasting) }\end{array}$ & $\begin{array}{l}\text { AG AUC } \\
\text { (EHC) }\end{array}$ \\
\hline Total energy intake & $r=0.37^{*}$ & $r=0.46^{\dagger}$ \\
Total carbohydrate intake & $\mathrm{NS}$ & $r=0.41^{*}$ \\
Total lipid intake & $\mathrm{NS}$ & $r=0.37^{*}$ \\
Monounsaturated lipid intake & $r=0.40^{\star}$ & $r=0.41^{*}$ \\
Polyunsaturated lipid intake & $r=0.41^{*}$ & $r=0.46^{\dagger}$ \\
Omega-3 intake & $r=0.35^{\star}$ & $r=0.41^{*}$ \\
Fiber intake & $r=0.47^{\dagger}$ & $r=0.45^{\dagger}$ \\
\hline $\begin{array}{l}\text { AG, acylated ghrelin; EHC, euglycemic/hyperinsulinemic clamp; } \text { AUC, area } \\
\text { under the curve. }{ }^{\star} P<0.05 ;{ }^{\dagger} P<0.01 .\end{array}$
\end{tabular}

Furthermore, VAT was also negatively associated with AG values, both in the fasted state $(r=-0.42$; $P<0.05$ ) and during the clamp (AUC; $r=-0.43$; $P<0.01)$ but not with TotG. Fasting and clamp AG values also correlated with total body weight (fasting: $r=-0.38 ; P<0.05$; AUC: $r=-0.34 ; P<0.05)$ and total fat mass (fasting: $r=-0.38 ; P<0.02$; EHC AUC value: $r=-0.36 ; P<0.03)$.

\section{Discussion}

Although ghrelin is a well-recognized orexigenic factor that can exert potent metabolic effects $(2-4)$, the specific mechanisms regulating its levels remain to be clarified. Previous investigations have suggested that while insulin is an important modulator of ghrelin $(33,34)$, additional factors also influence its levels (35). The primary objective of this study was to evaluate whether consumption of specific macronutrients derived from the diet could influence TotG and AG profiles in both fasting and hyperinsulinemic conditions. The main result of the present study is that fiber intake may predict, at least in part, the unique variance of fasting AG and TotG as well as TotG AUC during an EHC in our cohort of overweight and obese postmenopausal women. By contrast, AG AUC was predicted primarily by total energy intake. This suggests that fiber consumption and energy intake could be associated with distinct regulatory mechanisms of AG in fasting and hyperinsulinemic conditions.

Compared to individuals with obesity, IR, and type 2 diabetes, lean healthy individuals present increased ghrelin levels in fasting conditions and showed an enhanced inhibitory capacity in postprandial conditions (6). As previously reported, during the $\mathrm{EHC}$, baseline values were significantly reduced at all times for TotG and only at time $60 \mathrm{~min}$ for AG (7). Studies have also demonstrated that subjects displaying a greater magnitude of TotG and AG reduction during the clamp display better metabolic profiles (7). In addition, increased fiber intake has been associated with a reduced risk for both type 2 diabetes and cardiovascular disease (22-24). 
Table 5 Stepwise regression analysis regarding independent predictors of total ghrelin (TotG) and acylated ghrelin (AG) variations.

\begin{tabular}{|c|c|c|c|c|c|c|c|}
\hline $\begin{array}{l}\text { Dependent } \\
\text { variable }\end{array}$ & Step & $\begin{array}{l}\text { Independent } \\
\text { variable }\end{array}$ & $\begin{array}{c}\text { Relationship } \\
( \pm)\end{array}$ & Partial $r^{2}$ & $\begin{array}{c}\text { Total } r^{2} \\
\text { cumulative }\end{array}$ & $\beta$-Coefficients & $P$ value \\
\hline Fasting TotG & 1 & Fiber intake & + & 0.26 & 0.26 & 0.51 & 0.002 \\
\hline TotG AUC & 1 & Fiber intake & + & 0.21 & 0.21 & 0.46 & 0.005 \\
\hline Fasting AG & 1 & Fiber intake & + & 0.23 & 0.23 & 0.47 & 0.004 \\
\hline \multirow[t]{2}{*}{ AG AUC } & 1 & $\begin{array}{l}\text { Total energy } \\
\text { intake }\end{array}$ & + & 0.21 & 0.21 & 0.46 & 0.006 \\
\hline & 2 & Omega-3 intake & + & 0.12 & 0.33 & 0.35 & 0.02 \\
\hline
\end{tabular}

TotG, total ghrelin; AG, acylated ghrelin; AUC, area under the curve.

In the present study, high fiber intake was positively associated with increased ghrelin levels in the fasted state as well as AG and TotG AUC values during the EHC. Thus, the consumption of a fiber-rich diet was associated with a ghrelin profile that is more representative of the one observed in healthy lean individuals. Other studies have suggested that fiber ingestion can modulate ghrelin profiles. Both acute fiber ingestion as well as the consumption of lupin-enriched bread containing a high proportion of fiber (25-30\%) were shown to reduce postprandial ghrelin levels $(36,37)$. The present study indicates the importance of total fiber consumption on the regulation of ghrelin profiles. However, other factors such as the physico-chemical nature (soluble versus insoluble) of the ingested fibers are also likely to have an impact (reviewed by Kathunen (38)). For instance, the ingestion of non-caloric soluble psyllium fibers reduced TotG AUC to an equivalent extent as the one observed following the ingestion of a mixed meal. Similar results were observed following the consumption of bread enriched with insoluble oat fibers $(39,40)$. The addition of carob pulp to an isocaloric liquid meal reduced postprandial AG but not TotG levels (36). Carob pulp is rich in compounds such as polyphenols, and it is not presently possible to distinguish whether this effect is directly mediated by the fibers or by other bioactive factors present in the pulp. Further investigations should focus on the impact of dietary fiber types on ghrelin levels in both the fasted state and postprandial condition.

High fiber consumption is associated with improved glucose homeostasis and insulin sensitivity (20, 22). Since glucose and insulin are important modulators of ghrelin levels $(6,7)$, we also evaluated whether these factors influence the association between ghrelin and fiber intake. Interestingly, fiber intake remained significantly associated with ghrelin levels (total or acylated) after correcting for insulin sensitivity. Recent studies have shown that high fiber intake increased the perception of satiety, reduced appetite, and lowered food intake in patients submitted to a standardized meal (41), and it was suggested that this effect could be due to increased gastric transit time (42-44). Potentially, decreased gastric emptying could result in better inhibition of ghrelin secretion in the upper section of the gastrointestinal tract. Fiber can have a delayed effect, reducing the glycemic response to the subsequent meal (45). In addition, fiber intake has also been associated with reduced IL-6 and tumour necrosis factor- $\alpha$-receptor-2 (46). Together, these effects may result in improved ghrelin profiles. Further studies exploring the influence of high fiber consumption on ghrelin levels will be needed to address the mechanism by which fiber influences ghrelin levels.
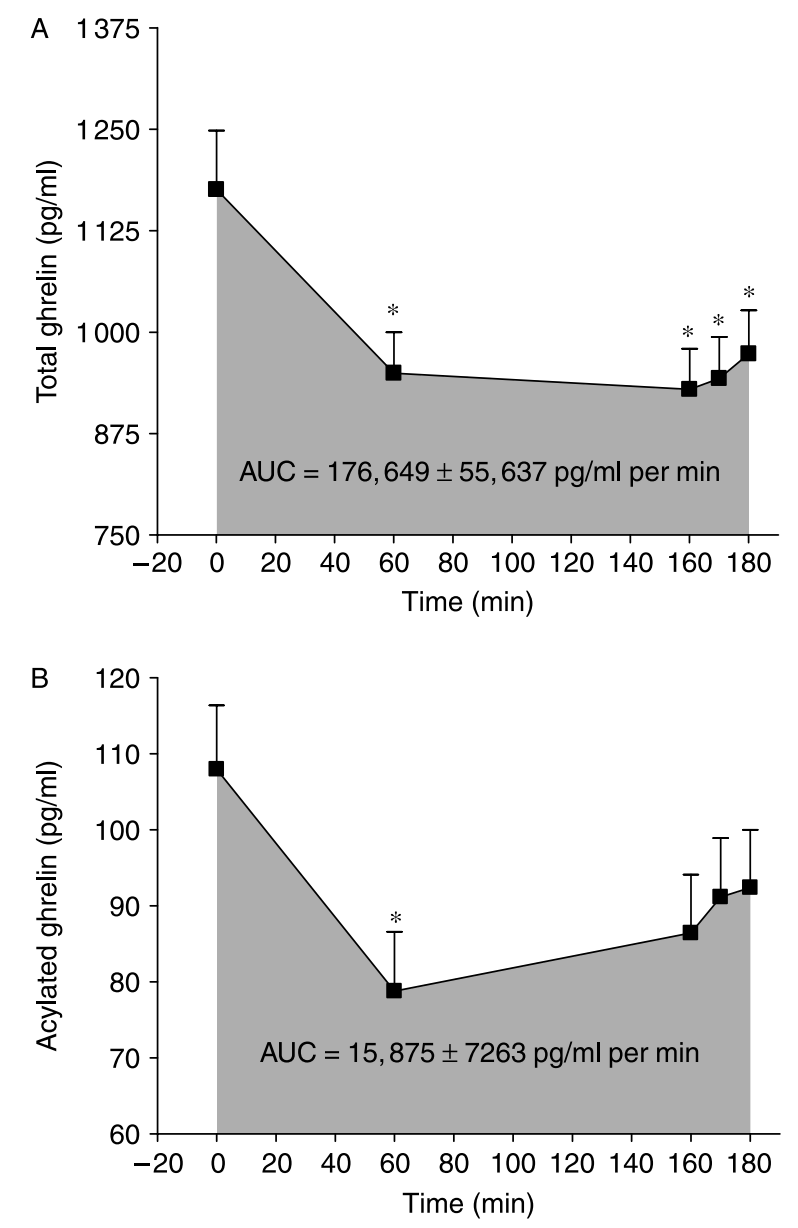

Figure 1 TotG $(A)$ and $A G(B)$ levels at baseline and throughout the euglycemic-hyperinsulinemic clamp in overweight and obese postmenopausal women. Significant reduction $\left({ }^{*}\right)$ from baseline levels were observed at all times $(60,160,170$, and $180 \mathrm{~min})$ for TotG, and only at time $60 \mathrm{~min}$ for $A G$. 
Total energy intake was the best predictor of AG AUC. In normal weight subjects, AG is recognized to be an important orexigenic factor (47) and postprandial TotG suppression is proportional to the ingested energy load (48). However, in obese subjects the latter effect could not be observed (49). Consumption of a high caloric meal ( $40 \%$ of daily calories) effectively suppressed TotG levels in obese subjects. Since only TotG levels were evaluated, AG regulation remains to be further examined.

Ghrelin plays an important role in promoting adiposity $(3,14)$, and it was suggested that its dysregulation could influence the development of metabolic disturbances associated with diet-induced obesity (50). In addition, excessive VAT accumulation is considered an important risk factor in the development of both type 2 diabetes and cardiovascular disease (51). Interestingly, VAT correlated negatively with both fasting and AG AUC values. Based on this information, it is tempting to hypothesize that reduced AG concentrations may mediate an adaptive feedback mechanism to prevent further increases in visceral adiposity. The present data also indicate that VAT was negatively correlated with consumption of fiber-rich diet. Numerous studies have highlighted the positive effect of high fiber consumption on lipid metabolism $(20,22,23,36$, 52). For example, the ingestion of dietary fibers may decrease postprandial triglycerides' and fatty acids' levels, possibly through reduced fat absorption. Furthermore, high fiber intakes were shown to increase fat oxidation and improve lipid metabolism while also modulating glucose homeostasis through the delay of glucose absorption. Thus, supplementation with dietary fibers could help prevent the development of metabolic disturbances through multiple mechanisms, which, in turn, could be mediated through the regulation of gastrointestinal hormones such as ghrelin.

The current study is limited by several factors. First, our cohort is composed of non-diabetic overweight and obese sedentary postmenopausal women. Therefore, our findings are limited to this population. Secondly, we used a cross-sectional approach, which does not allow us to make conclusions on any causal associations. Thirdly, we infused high insulin levels to completely inhibit hepatic glucose production even in insulinresistant individuals (53). Thus, it is possible that a lower and more physiological dose of insulin might have influenced the association between fiber intake and $A G$ levels differently. Despite these limitations, our results are strengthened by the use of gold standard techniques for the evaluation of various metabolic risk factors in a relatively well-characterized cohort.

In conclusion, the present results provide new evidence of the association of TotG and AG profiles with fiber intake in a population of overweight and obese postmenopausal women. Ultimately, a better understanding of the relationship between ghrelin and fiber intake may lead to new clinical strategies aimed at improving metabolic profiles.

\section{Declaration of interest}

The authors declare no conflict of interest that could be perceived as prejudicing the impartiality of the research reported.

\section{Funding}

David H St-Pierre and Marie-Eve Lavoie are funded by the Canadian Institutes of Health Research (CIHR) and Fonds de la Recherche en Santé du Québec (FRSQ) doctoral fellowships respectively. Rémi Rabasa-Lhoret holds a J-A de Sève Chair for Clinical Research. Eric Doucet is a recipient of a CIHR/Merck-Frost New Investigator Award and CFI/OIT New Opportunities Award. This work was supported by grants from the CIHR New Emerging Teams in Obesity (Université de Montréal and University of Ottawa MONET project; grant number 63279) and from the CIHR Operating Grant (MOP62976).

\section{Acknowledgements}

We would like to thank Mrs Lyne Messier for the coordination of this study.

\section{References}

1 Kojima M, Hosoda H, Date $\mathrm{Y}$, Nakazato M, Matsuo H \& Kangawa K. Ghrelin is a growth-hormone-releasing acylated peptide from stomach. Nature 1999402 656-660.

2 Wiedmer P, Nogueiras R, Broglio F, D'Alessio D \& Tschop MH. Ghrelin, obesity and diabetes. Nature Clinical Practice. Endocrinology and Metabolism 20073 705-712.

3 Tschop M, Smiley DL \& Heiman ML. Ghrelin induces adiposity in rodents. Nature $2000 \mathbf{4 0 7} 908-913$.

4 Wren AM, Small CJ, Ward HL, Murphy KG, Dakin CL, Taheri S, Kennedy AR, Roberts GH, Morgan DG, Ghatei MA \& Bloom SR. The novel hypothalamic peptide ghrelin stimulates food intake and growth hormone secretion. Endocrinology 2000141 4325-4328.

5 De Vriese C \& Delporte C. Influence of ghrelin on food intake and energy homeostasis. Current Opinion in Clinical Nutrition and Metabolic Care 200710 615-619.

6 Shiiya T, Nakazato M, Mizuta M, Date Y, Mondal MS, Tanaka M, Nozoe S, Hosoda H, Kangawa K \& Matsukura S. Plasma ghrelin levels in lean and obese humans and the effect of glucose on ghrelin secretion. Journal of Clinical Endocrinology and Metabolism $200287240-244$.

7 St-Pierre DH, Karelis AD, Coderre L, Malita F, Fontaine J, Mignault D, Brochu M, Bastard JP, Cianflone K, Doucet E, Imbeault P \& Rabasa-Lhoret R. Association of acylated and nonacylated ghrelin with insulin sensitivity in overweight and obese postmenopausal women. Journal of Clinical Endocrinology and Metabolism 200792 264-269.

8 Cummings DE, Weigle DS, Frayo RS, Breen PA, Ma MK, Dellinger EP \& Purnell JQ. Plasma ghrelin levels after diet-induced weight loss or gastric bypass surgery. New England Journal of Medicine 2002346 1623-1630.

9 Broglio F, Gottero C, Prodam F, Gauna C, Muccioli G, Papotti M, Abribat T, Van Der Lely AJ \& Ghigo E. Non-acylated ghrelin counteracts the metabolic but not the neuroendocrine response to acylated ghrelin in humans. Journal of Clinical Endocrinology and Metabolism 200489 3062-3065.

10 Gauna C, Delhanty PJ, Hofland LJ, Janssen JA, Broglio F, Ross RJ, Ghigo E \& van der Lely AJ. Ghrelin stimulates, whereas desoctanoyl ghrelin inhibits, glucose output by primary hepatocytes. Journal of Clinical Endocrinology and Metabolism 200590 $1055-1060$.

11 Gauna C, Delhanty PJ, van Aken MO, Janssen JA, Themmen AP, Hofland LJ, Culler M, Broglio F, Ghigo E \& van der Lely AJ. Unacylated ghrelin is active on the INS-1E rat insulinoma cell line 
independently of the growth hormone secretagogue receptor type $1 \mathrm{a}$ and the corticotropin releasing factor 2 receptor. Molecular and Cellular Endocrinology 2006251 103-111.

12 Gauna C, Kiewiet RM, Janssen JA, van de Zande B, Delhanty PJ, Ghigo E, Hofland LJ, Themmen AP \& van der Lely AJ. Unacylated ghrelin acts as a potent insulin secretagogue in glucose-stimulated conditions. American Journal of Physiology. Endocrinology and Metabolism 2007293 E697-E704.

13 Gauna C, Meyler FM, Janssen JA, Delhanty PJ, Abribat T, van Koetsveld P, Hofland LJ, Broglio F, Ghigo E \& van der Lely AJ. Administration of acylated ghrelin reduces insulin sensitivity, whereas the combination of acylated plus unacylated ghrelin strongly improves insulin sensitivity. Journal of Clinical Endocrinology and Metabolism 200489 5035-5042.

14 Cummings DE. Ghrelin and the short- and long-term regulation of appetite and body weight. Physiology and Behaviour 200689 71-84.

15 Gerstein DE, Woodward-Lopez G, Evans AE, Kelsey K \& Drewnowski A. Clarifying concepts about macronutrients' effects on satiation and satiety. Journal of the American Dietetic Association 2004104 1151-1153.

16 Foster-Schubert KE, Overduin J, Prudom CE, Liu J, Callahan HS, Gaylinn BD, Thorner MO \& Cummings DE. Acyl and total ghrelin are suppressed strongly by ingested proteins, weakly by lipids, and biphasically by carbohydrates. Journal of Clinical Endocrinology and Metabolism 200893 1971-1979.

17 Marzullo P, Caumo A, Savia G, Verti B, Walker GE, Maestrini S, Tagliaferri A, Di Blasio AM \& Liuzzi A. Predictors of postabsorptive ghrelin secretion after intake of different macronutrients. Journal of Clinical Endocrinology and Metabolism 2006 $914124-4130$.

18 Gomez G, Englander EW \& Greeley GH Jr. Nutrient inhibition of ghrelin secretion in the fasted rat. Regulatory Peptides 2004117 33-36.

19 Erdmann J, Lippl F \& Schusdziarra V. Differential effect of protein and fat on plasma ghrelin levels in man. Regulatory Peptides 2003 116 101-107.

20 Weickert MO \& Pfeiffer AF. Metabolic effects of dietary fiber consumption and prevention of diabetes. Journal of Nutrition 2008 138 439-442.

21 Slavin JL. Dietary fiber and body weight. Nutrition 200521 411-418.

22 Venn BJ \& Mann JI. Cereal grains, legumes and diabetes. European Journal of Clinical Nutrition $2004 \mathbf{5 8} 1443-1461$.

23 Lairon D. Macronutrient intake and modulation on chylomicron production and clearance. Atherosclerosis $2008945-48$.

24 Kan H, Stevens J, Heiss G, Klein R, Rose KM \& London SJ. Dietary fiber intake and retinal vascular caliber in the Atherosclerosis Risk in Communities Study. American Journal of Clinical Nutrition 2007 86 1626-1632.

25 Broglio F, Arvat E, Benso A, Gottero C, Muccioli G, Papotti M, van der Lely AJ, Deghenghi R \& Ghigo E. Ghrelin, a natural GH secretagogue produced by the stomach, induces hyperglycemia and reduces insulin secretion in humans. Journal of Clinical Endocrinology and Metabolism 200186 5083-5086.

26 St-Pierre DH, Karelis AD, Cianflone K, Conus F, Mignault D, Rabasa-Lhoret R, St-Onge M, Tremblay-Lebeau A \& Poehlman ET. Relationship between ghrelin and energy expenditure in healthy young women. Journal of Clinical Endocrinology and Metabolism 200489 5993-5997.

27 St-Pierre DH, Bastard JP, Coderre L, Brochu M, Karelis AD, Lavoie ME, Malita F, Fontaine J, Mignault D, Cianflone K, Imbeault P, Doucet E \& Rabasa-Lhoret R. Association of acylated ghrelin profiles with chronic inflammatory markers in overweight and obese postmenopausal women: a MONET study. European Journal of Endocrinology 2007157 419-426.

28 DeFronzo RA, Tobin JD \& Andres R. Glucose clamp technique: a method for quantifying insulin secretion and resistance. American Journal of Physiology 1979237 E214-E223.
29 Friedewald WT, Levy RI \& Fredrickson DS. Estimation of the concentration of low-density lipoprotein cholesterol in plasma, without use of the preparative ultracentrifuge. Clinical Chemistry 197218 499-502.

30 Matthews DR, Hosker JP, Rudenski AS, Naylor BA, Treacher DF \& Turner RC. Homeostasis model assessment: insulin resistance and beta-cell function from fasting plasma glucose and insulin concentrations in man. Diabetologia 198528 412-419.

31 Brochu M, Tchernof A, Dionne IJ, Sites CK, Eltabbakh GH, Sims EA \& Poehlman ET. What are the physical characteristics associated with a normal metabolic profile despite a high level of obesity in postmenopausal women? Journal of Clinical Endocrinology and Metabolism 200186 1020-1025.

32 Bernier P \& Laurent L. Evaluation nutritionelle. In Manuel de Nutrition Clinique. Ordre professionnel des dietetistes du Quebec, edn 3, Ch 1.2, p 4. Ed Guy Connolly. Montreal, Québec, Canada, 2000.

33 Murdolo G, Lucidi P, Di Loreto C, Parlanti N, De Cicco A, Fatone C, Fanelli CG, Bolli GB, Santeusanio F \& De Feo P. Insulin is required for prandial ghrelin suppression in humans. Diabetes 200352 2923-2927.

34 Mohlig M, Spranger J, Otto B, Ristow M, Tschop M \& Pfeiffer AF. Euglycemic hyperinsulinemia, but not lipid infusion, decreases circulating ghrelin levels in humans. Journal of Endocrinological Investigation 200225 RC36-RC38.

35 Spranger J, Ristow M, Otto B, Heldwein W, Tschop M, Pfeiffer AF \& Mohlig M. Post-prandial decrease of human plasma ghrelin in the absence of insulin. Journal of Endocrinological Investigation $2003 \mathbf{2 6}$ RC19-RC22.

36 Gruendel S, Garcia AL, Otto B, Mueller C, Steiniger J, Weickert MO, Speth M, Katz N \& Koebnick C. Carob pulp preparation rich in insoluble dietary fiber and polyphenols enhances lipid oxidation and lowers postprandial acylated ghrelin in humans. Journal of Nutrition $20061361533-1538$.

37 Lee YP, Mori TA, Sipsas S, Barden A, Puddey IB, Burke V, Hall RS \& Hodgson JM. Lupin-enriched bread increases satiety and reduces energy intake acutely. American Journal of Clinical Nutrition 2006 84 975-980.

38 Karhunen LJ, Juvonen KR, Huotari A, Purhonen AK \& Herzig KH. Effect of protein, fat, carbohydrate and fibre on gastrointestinal peptide release in humans. Regulatory Peptides 2008 149 70-78.

39 Nedvidkova J, Krykorkova I, Bartak V, Papezova H, Gold PW, Alesci S \& Pacak K. Loss of meal-induced decrease in plasma ghrelin levels in patients with anorexia nervosa. Journal of Clinical Endocrinology and Metabolism 200388 1678-1682.

40 Weickert MO, Spranger J, Holst JJ, Otto B, Koebnick C, Mohlig M \& Pfeiffer AF. Wheat-fibre-induced changes of postprandial peptide YY and ghrelin responses are not associated with acute alterations of satiety. British Journal of Nutrition 200696 795-798.

41 Nilsson AC, Ostman EM, Holst JJ \& Bjorck IM. Including indigestible carbohydrates in the evening meal of healthy subjects improves glucose tolerance, lowers inflammatory markers, and increases satiety after a subsequent standardized breakfast. Journal of Nutrition 2008138 732-739.

42 Vuksan V, Whitham D, Sievenpiper JL, Jenkins AL, Rogovik AL, Bazinet RP, Vidgen E \& Hanna A. Supplementation of conventional therapy with the novel grain Salba (Salvia hispanica L.) improves major and emerging cardiovascular risk factors in type 2 diabetes: results of a randomized controlled trial. Diabetes Care $2007 \mathbf{3 0}$ 2804-2810.

43 Kaline K, Bornstein SR, Bergmann A, Hauner H \& Schwarz PE. The importance and effect of dietary fiber in diabetes prevention with particular consideration of whole grain products. Hormone and Metabolic Research 200739 687-693.

44 Salas-Salvado J, Farres X, Luque X, Narejos S, Borrell M, Basora J, Anguera A, Torres F, Bullo M \& Balanza R. Effect of two doses of a mixture of soluble fibres on body weight and metabolic variables in overweight or obese patients: a randomised trial. British Journal of Nutrition 200899 1380-1387. 
45 Samra RA \& Anderson GH. Insoluble cereal fiber reduces appetite and short-term food intake and glycemic response to food consumed $75 \mathrm{~min}$ later by healthy men. American Journal of Clinical Nutrition $200786972-979$.

46 Ma Y, Hebert JR, Li W, Bertone-Johnson ER, Olendzki B, Pagoto SL, Tinker L, Rosal MC, Ockene IS, Ockene JK, Griffith JA \& Liu S. Association between dietary fiber and markers of systemic inflammation in the Women's Health Initiative Observational Study. Nutrition $2008 \mathbf{2 4}$ 941-949.

47 Schmid DA, Held K, Ising M, Uhr M, Weikel JC \& Steiger A. Ghrelin stimulates appetite, imagination of food, GH, ACTH, and cortisol, but does not affect leptin in normal controls. Neuropsychopharmacology 200530 1187-1192.

48 Callahan HS, Cummings DE, Pepe MS, Breen PA, Matthys CC \& Weigle DS. Postprandial suppression of plasma ghrelin level is proportional to ingested caloric load but does not predict intermeal interval in humans. Journal of Clinical Endocrinology and Metabolism 200489 1319-1324.

49 le Roux CW, Patterson M, Vincent RP, Hunt C, Ghatei MA \& Bloom SR. Postprandial plasma ghrelin is suppressed proportional to meal calorie content in normal-weight but not obese subjects. Journal of Clinical Endocrinology and Metabolism 200590 1068-1071.

50 Schneeman BO. Gastrointestinal physiology and functions. British Journal of Nutrition $2002 \mathbf{8 8}$ S159-S163.

51 Despres JP. Intra-abdominal obesity: an untreated risk factor for type 2 diabetes and cardiovascular disease. Journal of Endocrinological Investigation 200629 77-82.

52 Schweizer TF \& Wursch P. The physiological and nutritional importance of dietary fibre. Experientia 1991 47 181-186.

53 Karelis AD, Faraj M, Bastard JP, St-Pierre DH, Brochu M, Prud'homme D \& Rabasa-Lhoret R. The metabolically healthy but obese individual presents a favorable inflammation profile. Journal of Clinical Endocrinology and Metabolism 200590 4145-4150.

Received 30 March 2009

Accepted 4 April 2009 